\title{
Effect of Pressure Ratio on Film Cooling of Turbine Aerofoil Using CFD
}

\author{
Vibhor Baghel $^{1}$, Sunil Chandel ${ }^{1, *}$, R. Sivasankara Reddy ${ }^{2}$ \\ ${ }^{1}$ Mechanical Engg Dept, DIAT (DU), Pune, India \\ ${ }^{2} \mathrm{Sc}$ 'F', Gas Turbine Research Establishment, Bangalore, India \\ *Corresponding Author: sunilchandel@diat.ac.in
}

Copyright (C) 2013 Horizon Research Publishing All rights reserved.

\begin{abstract}
Gas turbine blades are cooled internally and externally and one widely used blade cooling technique is film cooling. In this type of cooling, relatively cool air is injected from the inside of the blade to the outside surface which forms a protective layer between the blade surface and hot gas streams. The present study is an attempt to establish the effect of blowing ratio and pressure ratio numerically on film cooling effectiveness in a typical nozzle guide vane with single hole on both pressure and suction surface of the vane. The commercially available CFD code "FLUENT" has been used after validating it against the experimental results reported in literature. Pressure ratio was varied from 1.1 to 1.2 with density ratio 2.0. Results obtained from the numerical investigation show that with increase in pressure ratio at constant blowing ratio, there was an increase in film cooling effectiveness. It is found that film spread is more on the pressure side as compared to suction side.
\end{abstract}

Keywords Film cooling, Blowing ratio, Pressure ratio, CFD

\section{Introduction}

The gas turbine industry is doing every hard work possible to take the gas turbine engine performance to greater heights. New engine designs are yielding engine efficiencies and thrust to weight ratio. The ability of today's gas turbine engine to withstand increasingly higher turbine-inlet temperatures has been largely due to advancement in cooling technology. Advances in the development of blade materials have not kept up with the ever-increasing thermal requirements. Cooling techniques have, therefore been developed to protect the blades from their extremely hot environment. Guide vanes are stationary and are used to guide the flow over the rotor blade smoothly and increase the velocity of the flow to the required extent. These guide vanes are the prime facie of high temperature high pressure gas coming out of combustion chamber when used for high pressure turbine. The future trend in engine design is to increase the turbine inlet temperature and to increase the temperature difference between free stream gas and the blade surface in order to obtain higher power to weight ratio. In order to do so, better understanding of cooling methods is essential.

Ravitej et al. [1] have presented the effect of radius of curvature on film cooling effectiveness. They found that on pressure surface, the magnitude of adiabatic effectiveness was lower and the decay of adiabatic effectiveness is faster. Their results on film cooling effectiveness data on the suction surface indicates that at higher coolant to mainstream density ratio, the film cooling effectiveness decays faster and at larger downstream distances, the magnitude of effectiveness was lower as compared to that for lower coolant to main stream density ratio. Mayhew et al. [2] have described the effect of free stream turbulence on film cooling effectiveness for the flat plate having three holes. Three blowing rates was investigated by them for a model with three straight holes spaced diameters apart, with density ratio near unity. They found that the high free stream turbulence increases the area averaged effectiveness at high blowing rates, but decreases it at low blowing rates. At low blowing ratio, free stream turbulence clearly reduces the coverage area of the cooling air due to increased mixing with the main flow. Ligrani et al. [3] described the development and structure of flow downstream of two staggered rows of film cooling holes with compound angle orientations. Results are presented for an injectant to free stream density ratio $1.0 \&$ injectant blowing ratio from 0.5 to 1.5 . They investigated the effect of hole angle orientation for constant spanwise hole spacing and the effects of spanwise hole spacing when the hole angle orientation is constant. Result from the first comparison show that the compound angle injection configuration provides improved film cooling protection compared to a simple angle configuration. Results from the second comparison shows that spanwise average effectiveness values are 25 to $40 \%$ higher when $3 \mathrm{~d}$ spanwise hole spacing is compared with $3.9 \mathrm{~d}$ spanwise hole spacing for blowing ratio and $\mathrm{x} / \mathrm{d}$, for $\mathrm{x} / \mathrm{d}<40$. Ammari et al. [4] investigated the effect of density ratio of cooling films on the heat transfer coefficient on a flat plate using heat and mass 
transfer analogy. A density ratio of 1.0 was achieved using air as the injectant. Representative of turbine operating conditions (density ratios of 1.38 and 1.52) were obtained by using foreign gases. Through a single normal hole or through a row of holes spaced at three-diameter intervals the coolant fluids were injected at various blowing rates. The heat transfer coefficient is increased by injection, and increases with injection rate, for both $35^{\circ}$ and $90^{\circ}$ injection. The $90^{\circ}$ injection gives higher heat transfer coefficients in regions just downstream of the holes than $35^{\circ}$ injection, but far downstream, the persistence of the structure of the $35^{\circ}$ jets yields higher heat transfer coefficients. Zhihong Gao et al. [5] studied the effect of compound angle shaped holes on film cooling on a gas turbine blade. They measured the film cooling effectiveness on the surface of high pressure turbine blade using pressure sensitive paint technique. The coolant is only injected to either the pressure side or suction side of the blade at five average blowing ratio ranging from 0.4 to 1.5 . Results reveal that film cooling effectiveness on the suction side is usually higher than that on the pressure side except the regions affected by the secondary vortices. Moderate blowing ratios show better film cooling effectiveness on pressure side as well as on suction side immediately downstream of the film cooling holes. Further, downstream of the film cooling holes, high blowing ratios provide wider film coverage. Gritsch et al. [6] have conducted experiments and their results revealed that holes with expanded exits have profoundly lower heat transfer coefficients at elevated blowing ratios as compared to a cylindrical hole and the laidback fan shaped hole provides better lateral spreading of the jet as compared to the fan shaped hole and, therefore, lower laterally averaged heat transfer coefficients. Coolant cross-flow Mach number has an impact on Film-cooling performance in the near-hole region, particularly for the shaped holes. Therefore, cross-flow at the hole entry side has to be taken into account when modeling film-cooling at engine representative conditions.

Study of above literatures emphasizes that no sustained attempt has been made to study the film cooling effectiveness on turbine aerofoil. Due to this reason, an attempt has been made to investigate the film cooling effectiveness on turbine aerofoil using CFD software FLUENT $^{\circledR}$. The present study investigates the effect of pressure ratio on film cooling effectiveness in a typical nozzle guide vane with single hole on both pressure and suction surface of the vane using CFD.

\section{Mathematical Model}

A commercially available CFD code 'FLUENT' [8] has been used for analyzing the turbulent flow. The details of the mathematical model are given in the manual of the code.

\section{Transport Equations for the Standard k- $\varepsilon$ Model}

The turbulence kinetic energy, $k$, and its rate of dissipation, $\varepsilon$, are obtained from the following transport equations:

$$
\begin{aligned}
\frac{\partial}{\partial t}(\rho k)+\frac{\partial}{\partial x_{i}}\left(\rho k u_{i}\right) & =\frac{\partial}{\partial x_{j}}\left[\left(\mu+\frac{\mu_{t}}{\sigma_{k}}\right) \frac{\partial k}{\partial x_{j}}\right]+G_{k}+G_{b}-\rho \epsilon-Y_{M}+S_{k} \\
\frac{\partial}{\partial t}(\rho \epsilon)+\frac{\partial}{\partial x_{i}}\left(\rho \epsilon u_{i}\right) & =\frac{\partial}{\partial x_{j}}\left[\left(\mu+\frac{\mu_{t}}{\sigma_{\epsilon}}\right) \frac{\partial \epsilon}{\partial x_{j}}\right]+C_{1 \epsilon} \frac{\epsilon}{k}\left(G_{k}+C_{3 \epsilon} G_{b}\right)-C_{2 \epsilon} \rho \frac{\epsilon^{2}}{k}+S_{\epsilon}
\end{aligned}
$$

In these equations, $G_{k}$ represents the generation of turbulence kinetic energy due to the mean velocity gradients. $G_{b}$ is the generation of turbulence kinetic energy due to buoyancy. $Y_{M}$ represents the contribution of the fluctuating dilatation in compressible turbulence to the overall dissipation rate. $C_{1 \varepsilon}, C_{2 \varepsilon}$, and $C_{3 \varepsilon}$ are constants. $\sigma_{k}$ and $\sigma_{\varepsilon}$ are the turbulent Prandtl numbers for $k$ and $\varepsilon$, respectively. $S_{k}$ and $S \varepsilon$ are user-defined source terms.

\section{Modeling the Turbulent Viscosity}

The turbulent (or eddy) viscosity, $\mu_{t}$, is computed by combining $k$ and $\varepsilon$ as follows:

$$
\mu_{t}=\rho C_{\mu} \frac{k^{2}}{\epsilon}
$$

where $C_{\mu}$ is a constant.

The model constants $C_{1 \varepsilon}, C_{2 \varepsilon}, C_{\mu}, \sigma_{k}$ and $\sigma_{\varepsilon}$ have the following default values:

$$
C_{1 \epsilon}=1.44, C_{2 \epsilon}=1.92, \quad C_{\mu}=0.09, \quad \sigma_{k}=1.0, \quad \sigma_{\epsilon}=1.3
$$

These default values have been determined from experiments with air and water for fundamental turbulent shear flows including homogeneous shear flows and decaying isotropic grid turbulence. They have been found to work fairly well for a wide range of wall-bounded and free shear flows.

\section{Discretization of the Geometry}

In the present work, a portion of the vane was modeled along with entry and exit lengths to make a proper flow domain (Fig. 1).

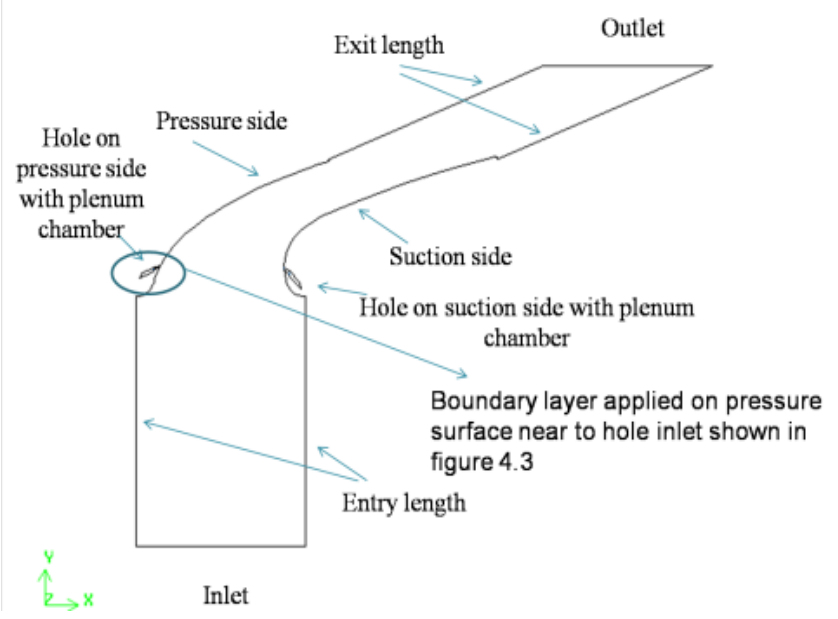

Figure 1. Flow domain with single hole on both pressure and suction surface

The entry and exit length were provided for giving direction to the flow and more importantly providing fully 
developed flow. The entry and exit length were modeled as fluid boundary. Flow domain is made periodic which is required for better flow visualization over the vane. The entry and exit lengths were modeled as fluid boundary. Fine mesh is required near to the vane surface in order to capture the velocity gradient near the vane. Boundary layer is applied on both suction and pressure side of the vane in order to capture the boundary layer phenomenon present in laminar sub-layer of the turbulent flow. The fluid domain extraction of the geometric model was carried out using AUTOCAD and GAMBIT software. The 2D flow domain was discretized using Quad elements which are used for surface meshing. Discretization of the flow domain was done using pave scheme, according to which it creates an unstructured grid of good quality elements which are suitable for further study in fluent. The discretized locations are referred to as the grid or mesh. Grid independency was done by carrying out flow simulation (Fig. 2).

Two different mesh with 200316 and 487073 cells respectively. Based on the result of grid independent study mesh with 200316 cells selected for further study.

\section{Boundary Conditions}

- The fluid flowing through the domain was considered as air.

- Boundary condition for entry and exit lengths was taken as interface (or fluid boundary).
- Boundary condition for blade surface, hole wall and plenum chamber walls was taken as adiabatic wall.

- Domain inlet and hole inlet was considered as pressure inlet.

- Domain outlet was taken as pressure outlet.

- Absolute values are used for boundary conditions.

\section{Solution Scheme}

The two-dimensional flow simulations have been carried out using CFD code "FLUENT" which is based on cell centered finite volume approach to solve the Partial Differential Equation. Using implicit scheme flow equations were solved with segregated solver for faster convergence. The second-order upwind scheme was used for discretization of all equations for more precise results. Under relaxation factor were used for all equations to satisfy the Scarborough condition for convergence. A convergence criterion of $10^{-6}$ was specified for residuals of all parameters.

\section{Validation of the Code}

A preliminary investigation has been done to validate the CFD code with the experimental results. For this purpose, Mach number distribution over the blade surface (both suction and pressure surface) is shown in Fig. 3 and Fig. 4.

\section{Grid Independent Study}

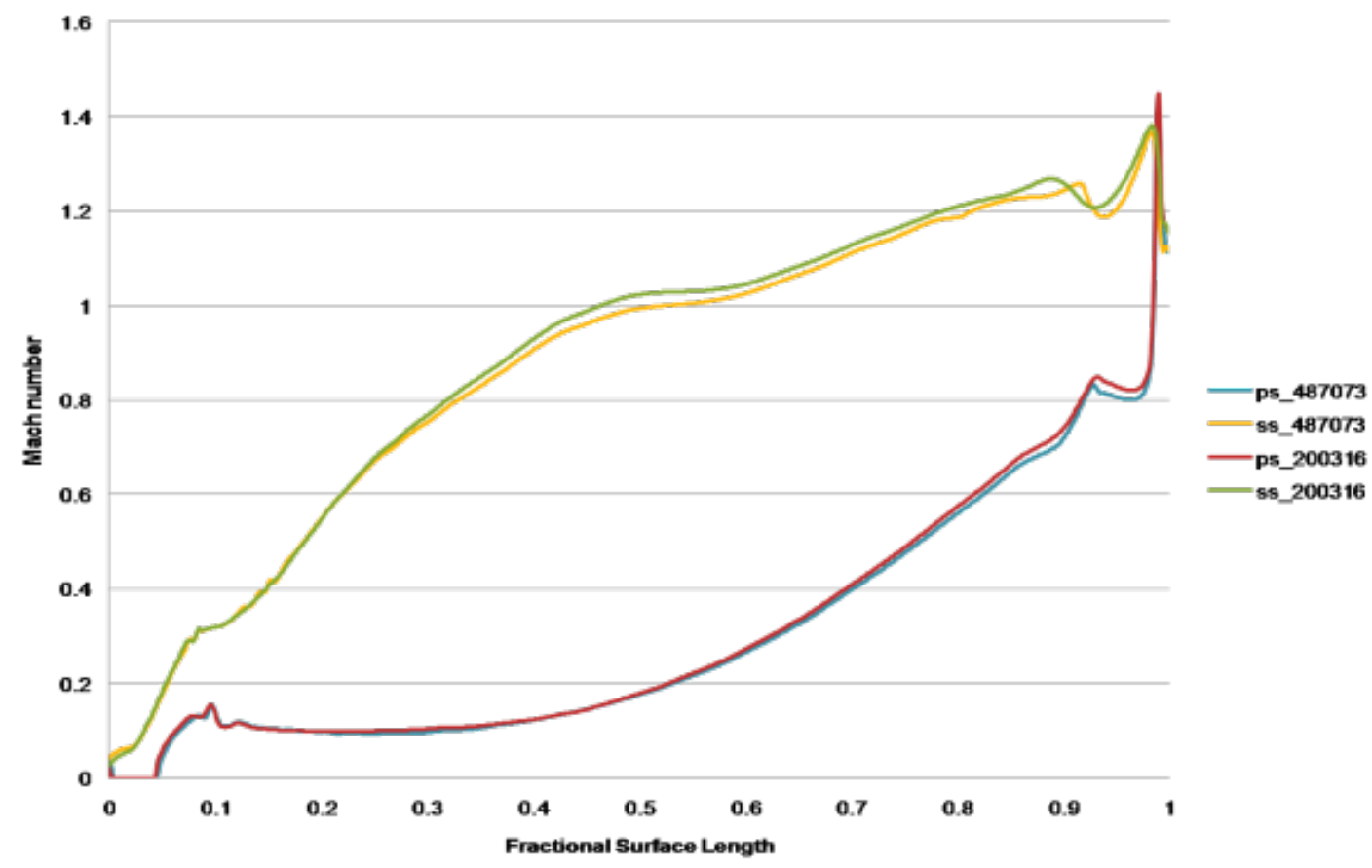

Figure 2. Mach number comparisons for grid independence study 


\section{Mach number Comparison For Standard $\kappa-\varepsilon$ with Enhanced Wall Treatment}

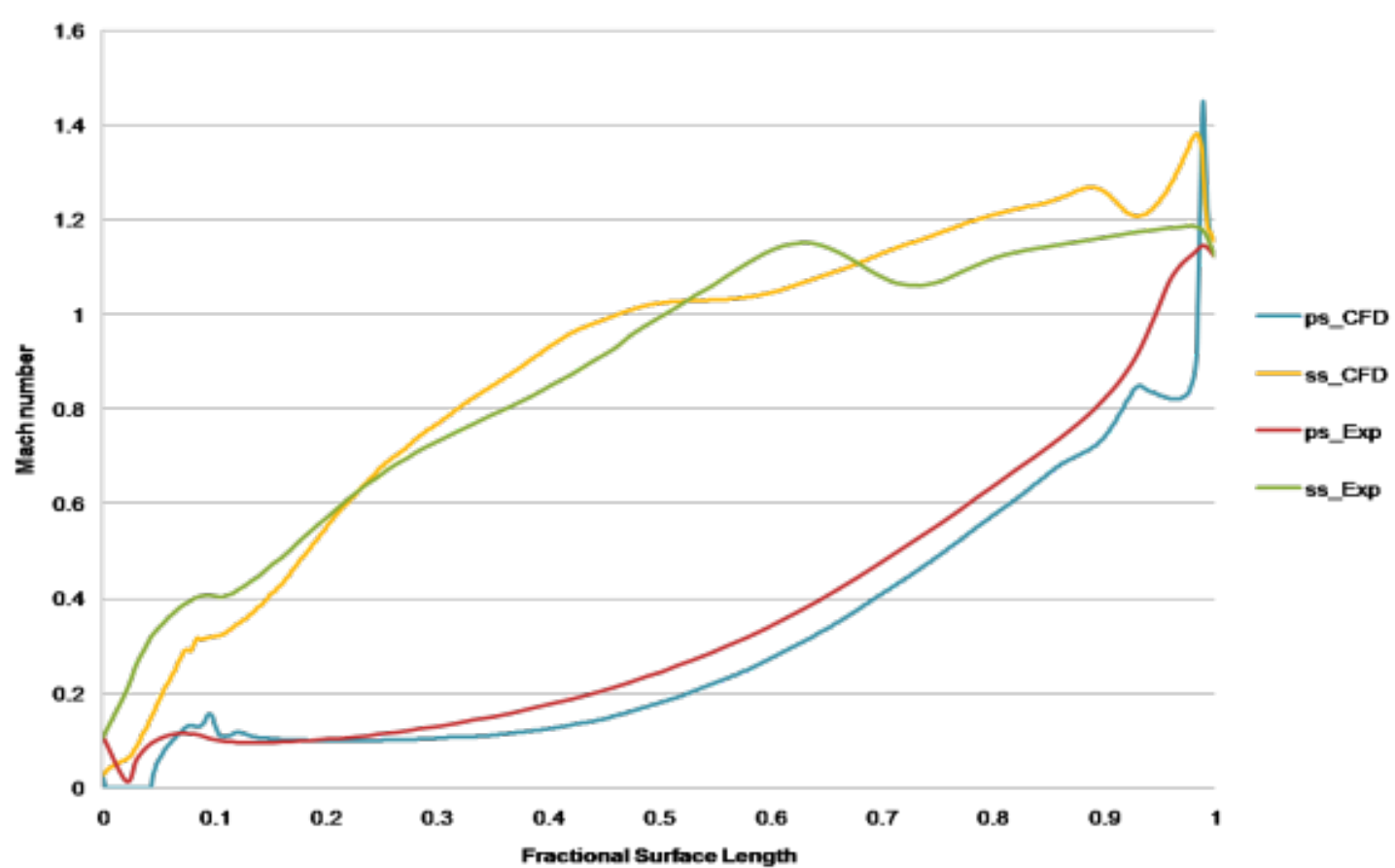

Figure 3. Mach number distributions over the blade surface using Standard $\kappa-\varepsilon$ Turbulence Model

\section{Mach number Comparison Using $\kappa-\omega$ Turubulence model}

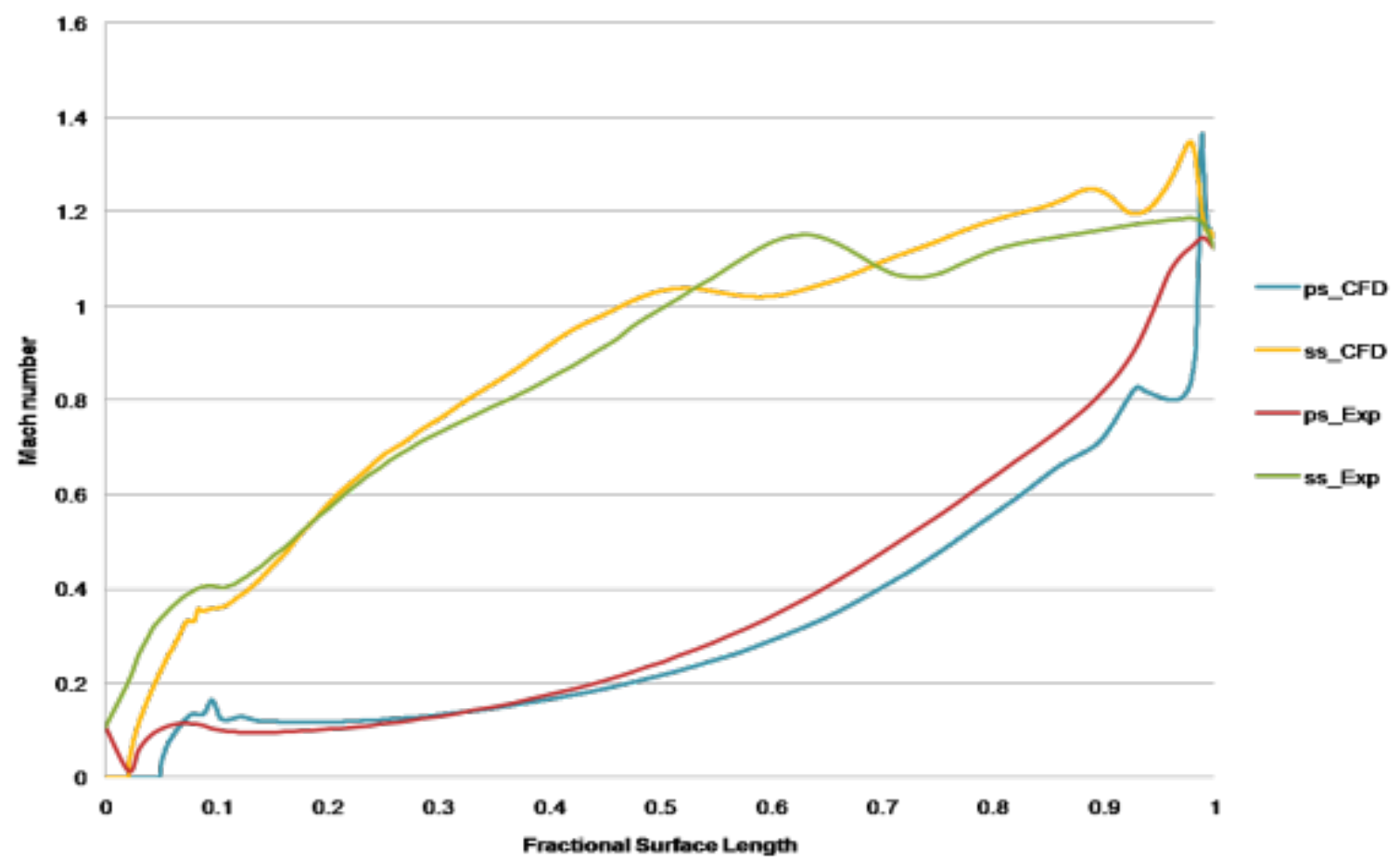

Figure 4. Mach number distributions over the blade surface using Standard $\kappa-\omega$ Turbulence Model 
The Mach number value starts increasing with the decrease in area and reaches unity at the throat and thereafter due to expansion it again accelerates and there is oblique shock wave which will reduce the mach number and its distribution on the vane surface is matching for all the cases but it is more accurate in case of Standard $k-\varepsilon$ and Standard $\kappa-\omega$ turbulence models, but as we know that the flow coming out of combustion chamber is highly turbulent and the Standard $\kappa-\varepsilon$ turbulence model is good for high turbulent cases. Hence For further investigation Standard $\kappa-\varepsilon$ turbulence model is used. It is also seen that the maximum deviation between experiments and predictions is less than \pm $10 \%$.

\section{Range of Parameters}

Film cooling study was performed with single hole on both suction and pressure side of vane and in subsequent figures fluid flow through the cooling hole is shown for both sides of the vane. Effect of varying the pressure ratio (pr) from 1.1, 1.15 and 1.2 is studied at different blowing ratios (BR) from 0.5, 1, 2 and 4 and the results are plotted against dimensionless downward distance. Static temperature variation is plotted in different views and it clearly shows the entry of cooling fluid and the film coverage on respective vane sides.

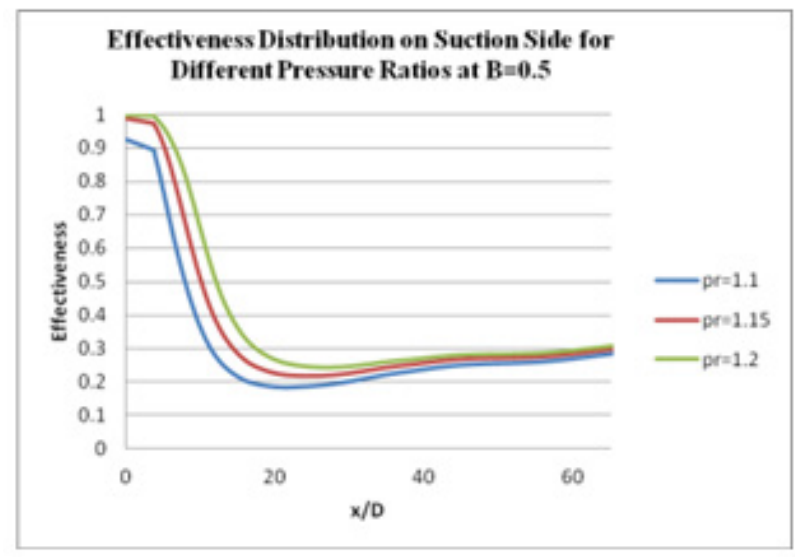

(a) $\mathrm{BR}=0.50$

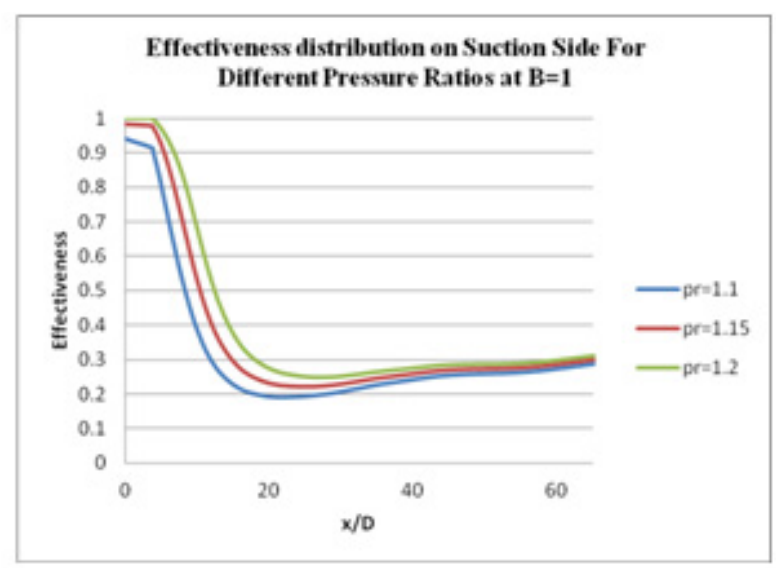

(b) $\mathrm{BR}=1.0$

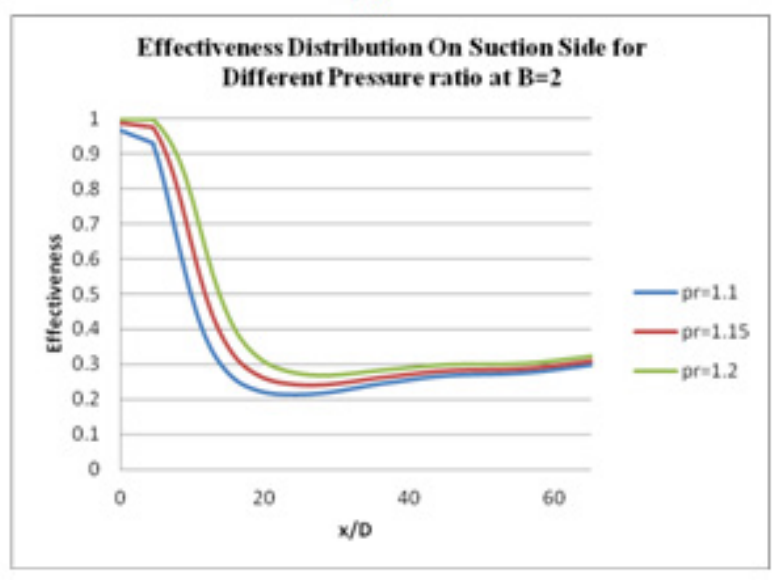

(c) $\mathrm{BR}=2.0$

Figure 5. Effectiveness distributions on suction surface for different Pressure ratios at various Blowing ratios

\section{Results and Discussion}

The emphasis of the present study is to study the effect of pressure ratio on film cooling effectiveness.

The effectiveness distribution for different pressure ratio (pr) on suction side at various blowing ratios (BR) are shown in Figs. 5 (a-c).

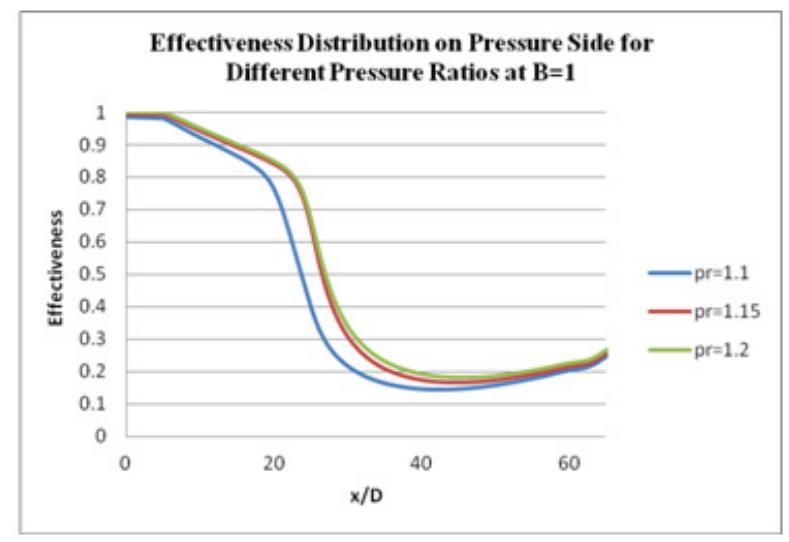

(a) $\mathrm{BR}=1$

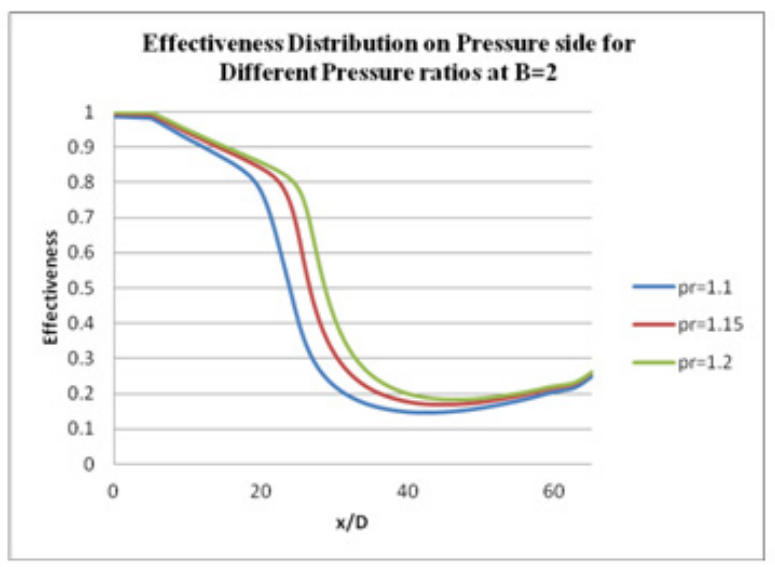

(b) $\mathrm{BR}=2$ 


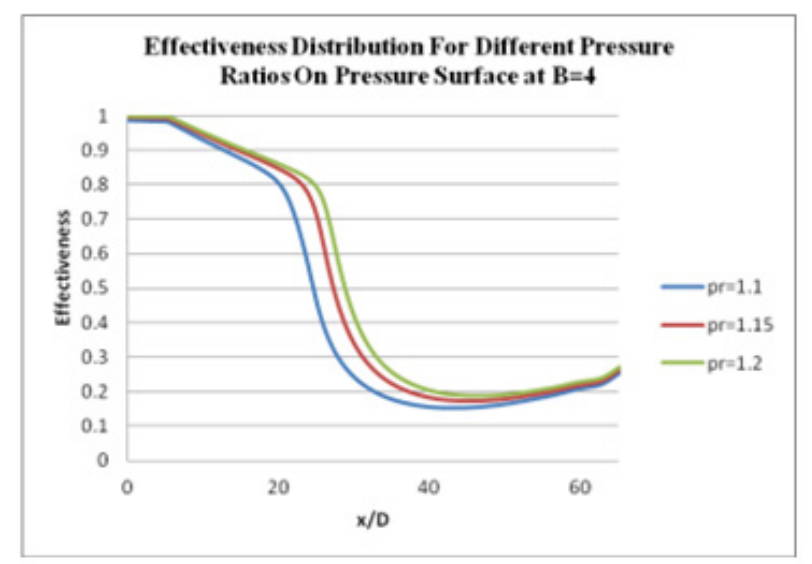

(c) $\mathrm{BR}=4$

Figure 6. Effectiveness distributions on Pressure side for different Pressure ratios at various Blowing ratios

The effect of increasing in pressure ratio from 1.1 to 1.2 resulted in increase in film cooling effectiveness as well as in film spread. On suction side, film is stable up to $\mathrm{x} / \mathrm{d}=10$ and collapses due to mixing of coolant with the hot main gas stream and later film effectiveness increases which is due to curvature effects and this short film spread as compared is due to cross flow pressure gradients.

The effectiveness distribution for different pressure ratio on pressure side at various blowing ratios are shown in Figs. 6 (a-c).

On pressure side, the effect is same as compared to suction side and here the film is stable up to $x / D=20$ and then it collapses due mixing of coolant with the hot main gas stream and later there is increase in film effectiveness which is due to curvature of the surface. The effect of increasing pressure ratio for constant blowing ratio shows that the film effectiveness value increases with increase in pressure ratio and film coverage also increases with increase in pressure ratio. This effect is same for all blowing ratios namely 1.0 , 2.0 and 4.0 on the pressure side and $0.5,1.0$ and 2.0 on suction side of the vane. Film spread is higher on pressure side as compared to suction side and blowing ratio required for same effectiveness is less on suction side as compared to on pressure side.

\section{Conclusions}

The CFD study using ANSYS FLUENT has been done for the flow through the passage between the typical nozzle guide vanes for analyzing the effects of variation of film cooling parameter on film cooling effectiveness. From the present study, the following important conclusions have been drawn.

- Film effectiveness increases with increase in pressure ratio for constant blowing ratio on both sides namely pressure side and suction side.

- Film spread is more on pressure side as compared to suction side due cross-flow pressure gradients between suction and pressure side.

- This study could not capture the effects of entrainment of hot gas in the gap between the holes and its effect on film effectiveness. A thorough 3-dimensional analysis is needed to capture the entrainment effects.

\section{REFERENCES}

[1] Ravitej, M., Kesavan, V., Krishnamoorthy, V., Felix, J. and Deepak, J., "Cooling Effectiveness Measurements Of Film Cooling Configuration of the Suction and Pressure Surface of the Nozzle Guide Vane," International Conference on Aerospace Science and Technology, No. 36, June 2008.

[2] Mayhew, James E., Baughn, James W., Byerley and Aaron R., "The Effect Of Free Stream Turbulence on Film Cooling Adiabatic Effectiveness," GT-2002-30172 ASME Turbo Expo 2002.

[3] Ligrani, P. M., Wigle, J. M., Ciriello, S. and Jackson, S. M., "Film Cooling from Holes with Compound Angle Orientations: Part 1- Result downstream of two staggered row of Holes with 3D Spanwise Spacing," Journal Of Heat Transfer, Vol. 116, May 1994, pp. 341-352.Ammari, H. D., Hay, N. and Lampard, D., "The Effect of Density Ratio on the Heat Transfer Coefficient from a Film-Cooled Flat Plate," ASME journal of heat transfer, Vol. 112, July 1990, pp. 444-450.

[4] Gao, Z., Narzary, D. P. and Han, J. C., "Film Cooling on a Gas Turbine Blade Pressure Side or Suction Side with Axial Shaped Holes," International Journal of Heat and Mass Transfer, , No. 51, 2008, pp. 2139-2152.

[5] Gritsch, M., Schulz, A. and Wittig, S., "Film Cooling Holes with Expanded Exits: Near Hole Heat Transfer Coefficients," International Journal Of Heat and Fluid Flow, 2000, pp 146-155.

[6] Han, J. C., Ekkad, S. V. and Dutta S., Gas Turbine Heat Transfer and Cooling Technology, Taylor \& Francis, 2000.

[7] FLUENT User Guide and Gambit User Guide. 